\title{
Functional activities of Philippine wild strain of Coprinus comatus (O. F. Müll. : Fr.) Pers and Pleurotus cystidiosus O. K. Miller grown on rice straw based substrate formulation
}

\author{
Kalaw $S^{1,2}$ and Albinto $\mathrm{RF}^{1}$ \\ ${ }^{I}$ Climate Change Center, Philippine Rice Research Institute, Maligaya, Science City of Muñoz, Nueva Ecija, \\ Philippines \\ ${ }^{2}$ Center for Tropical Mushroom Research and Development, Department of Biological Sciences, College of Arts and \\ Sciences, Central Luzon State University, Science City of Munoz, Nueva Ecija, Philippines
}

Kalaw SP, Albinto RF 2014 - Functional activities of Philippine wild strain of Coprinus comatus (O. F. Müll. : Fr.) Pers and Pleurotus cystidiosus O. K. Miller grown on rice straw based substrate formulation. Mycosphere 5(5), 646-655, Doi 10.5943/mycosphere/5/5/5

\begin{abstract}
In order to determine the nutraceutical and pharmacological potential of Philippine wild strain of Coprinus comatus and Pleurotus cystidiosus, the antibacterial property, phytochemical composition, and antioxidant activity were evaluated. Both ethanol and acetone basidiocarp extracts exhibited antibacterial activity against Staphylococcos aureus. Coprinus comatus ethanol extract produced wider zone of inhibition than acetone extract while Pleurotus cystidiosus acetone extract exhibited larger zone of inhibition than the ethanol extract. Moreover, the immobilized mycelia discs of both species did not exhibit antibacterial activity against Staphylococcos aureus and Escherichia coli. Phytochemical screening revealed the presence of alkaloids, flavonoids, saponins and terpenoids in both mushroom species. Steroids and cardiac glycosides were absent in Pleurotus cystidiosus while tannins were not detected in both species. Pleurotus cystidiosus registered higher DPPH radical scavenging activity and lower total phenolic content than Coprinus comatus.
\end{abstract}

Key words - antibacterial - antioxidant - phytochemical composition - rice straw

\section{Introduction}

The Philippines has a very rich and diverse species of macrofungi that are naturally growing on different substrates such as leaf litter, decaying plant residues and decomposing logs of trees particularly during rainy season. For instance, in Central Luzon region, De Leon et al. (2013a) reported 76 species of macrofungi in six Aeta tribal communities while Ellamar et al. (2009) identified 16 species of wild macrofungi in Camiling, Tarlac. Thirteen species were found edible with medicinal and pharmaceutical properties. In order to harness the potential of these wild genetic mycoresource as a source of food and pharmacological compounds, studies on the optimization of culture conditions for mycelial growth and fruiting body production of several species were undertaken namely: Collybia reinakeana (Reyes et al. 2004), Coprinus comatus (Reyes et al., 2009a), Lentinus sajor caju (Cuevas et al. 2009), Lentinus tigrinus (Dulay et al. 2012), Schizophyllum commune (Reyes et al. 2006), Ganoderma, Auricularia (Tayamen et al. 2004), Lentinus squarrosulus and Polyporus grammocephalus (De Leon 2013b). At present, these wild mushrooms can be artificially cultivated using rice straw based substrate formulations. 
Recently, due to many health benefits that can be derived from mushrooms, they are now considered as a nutraceutical food with functional activities. Several species have been reported to possess antibacterial (Reyes et al. 2006), anti-hypertensive (Reyes et al. 2009c), inhibition of platelet aggregation and anti-inflammatory (Reyes et al. 2013) and antioxidant activities (Turkuglo et. al 2007a, Turkuglo et al. 2007b).

Wild strains of Pleurotus cystidiosus and Coprinus comatus are usually found growing in the wild in different parts of the Philippines during rainy season. Pleurotus cystidiosus, commonly known as abalone, is a wood rotting mushroom that usually grows on decomposing logs. On the other hand, Coprinus comatus which is also called by the local people as devil's mushroom because of its inky appearance when mature, is a leaf litter decomposing mushroom that normally grow on pile of rice straw that competes with paddy straw mushrooms. The two species are potential source of bioactive compounds which can be used in the nutraceutical and pharmaceutical industry.

\section{Materials \& Methods}

\section{Source of cultures}

Pure cultures of Coprinus comatus and Pleurotus cystidiosus were obtained from the culture collection of the Center for Tropical Mushroom Research and Development, Department of Biological Sciences, Central Luzon State University, Science City of Muñoz, Nueva Ecija. They were sub cultured using potato dextrose agar.

\section{Production of fruiting bodies}

Pleurotus cystidiosus fruiting bodies were produced using rice straw based substrate formulation consisting of 7 parts rice straw and 3 parts saw dusts (v/v) following the protocol of Reyes et al. (2009b) while Coprinus comatus was grown on 7 parts rice straw +3 parts sawdust +1 part rice bran (v/v) based on the procedure outlined by Reyes et al. (2009a).

\section{Preparation of mushroom extract}

Air dried fruiting bodies were pulverized using waring blender. Ten grams of powdered materials was soaked in $100 \mathrm{ml}$ of solvent (ethanol and acetone) at room temperature for 24 hours and filtered using Whatman No. 2 filter paper. The filtrate was concentrated using a rotary evaporator at a temperature of $60{ }^{\circ} \mathrm{C}$. The extracts were stored in amber bottle in a refrigerator until use.

\section{Preparation of immmobilized secondary mycelial discs}

The procedure of Dulay et al (2014) on the preparation of immobilized mycelial discs was adopted. Briefly, Coprinus comatus and Pleurotus cystidiosus were separately cultured in potato dextrose agar plate. Before the complete ramification of mycelia on the entire medium, previously sterilized filter paper discs measuring $6 \mathrm{~mm}$ diameter were aseptically placed at the mycelia growth margin to allow mycelia growth on the filter paper discs. After complete mycelia colonization, filter paper discs with mushroom mycelia were harvested. The mycelia discs were immobilized in an oven at $40{ }^{\circ} \mathrm{C}$ for 2 days.

\section{Anti-bacterial assay}

The anti-bacterial activities of the extracts of Coprinus comatus and Pleurotus cystidiosus were evaluated following the procedure of Dulay et al. (2014) with minor modification. Staphylococcos aureus and Escherichia coli were cultured in $9 \mathrm{ml}$ of nutrient broth and incubated at $37{ }^{\circ} \mathrm{C}$. After 24 hours, the turbidity of the bacterial cultures was adjusted using $0.5 \mathrm{McFarland}$ standards, which is approximately $1.5 \times 10^{8} \mathrm{ml}^{-1}$. The bacterial suspension was spread using a sterile cotton swab on Mueller Hinton agar plates. Six millimeter diameter paper discs separately impregnated with ethanol and acetone extract $(20 \mu \mathrm{L})$, immobilized mycelia and streptomycin as standard were placed equidistantly on previously sterilized Mueller Hinton agar plate. Plates were 
incubated at $37{ }^{\circ} \mathrm{C}$, and the zones of inhibition were measured after 24 hours. Each treatment was replicated three times.

\section{Antioxidant assay}

DPPH radical scavenging activity. The free radical scavenging capacity of the mushroom samples was estimated using the stable 2, 2'- diphenyl-1-1 picrylhydrazyl (DPPH) radical according to procedure of Iqbal et al. (2005) with modifications. One gram of air dried powdered mushroom was extracted with $10 \mathrm{ml}$ of $85 \%$ methanol in an electrical shaker for $12 \mathrm{hrs}$ and centrifuged at $2,000 \mathrm{rpm}$ for 10 minutes. To $1.0 \mathrm{ml}$ of mushroom extract, $10 \mathrm{ml}$ of freshly prepared $0.1 \mathrm{mM} \mathrm{DPPH}$ solution was added. After one hour, the absorbance at $517 \mathrm{~nm}$ was taken and compared against blank and ascorbic acid and butylated hydroxyl anisole (BHA) standards. The radical scavenging activity (\%) was measured as a decrease in the absorbance of $0.1 \mathrm{~nm} \mathrm{DPPH}$ and was calculated using the formula:

$\%$ scavenging activity $=(1-$ A sample/A control $) \times 100$

where:

A sample $=$ absorbance in the presence of the sample or reference material

A control $=$ absorbance of the control containing all the reaction reagents

Total phenolic content. Total phenolic content was determined using the Folin-Ciocalteau procedure as cited by Adom and Liu (2002) with some modifications. Briefly, $1.0 \mathrm{~g}$ of powdered mushroom sample was mixed with $10 \mathrm{ml}$ of $60 \%(\mathrm{v} / \mathrm{v})$ acetone. The mixture was shaken for 15 minutes, centrifuged at $2000 \mathrm{rpm}$ for 15 minutes, and the supernatant was collected. The residue was re-extracted two times with $60 \%$ ethanol. The concentrate was then further oven dried at $30^{\circ} \mathrm{C}$. After drying, the residue was re-dissolved with distilled water up to $25.0 \mathrm{~mL}$ and then stored at 4 ${ }^{\circ} \mathrm{C}$, until analysis. Five hundred microliters $(500 \mathrm{uL})$ of the extract was added with $2.5 \mathrm{~mL}$ of Follin - Ciocalteau's phenol reagent (1/10 dilution). It was allowed to stand at room temperature for 15 minutes and then $2.0 \mathrm{~mL}$ of $7.5 \%$ sodium carbonate was added. After 1 hour of color development, the absorbance of the mixture was measured at $765 \mathrm{~nm}$ against a blank and gallic acid standards (0$100 \mathrm{ug} / \mathrm{mL}$ ). Phenolic content was calculated based on the standard and values were expressed in gallic acid equivalent (GAE) per gram of sample.

Phenolics Content $=\mathrm{A} \times 25 /$ weight of sample $(\mathrm{g}) \times \mathrm{MW}_{\mathrm{GA}}$

where:

A $=u g / g$ ferulic acid based on calibration curve

$\mathrm{MW}_{\mathrm{GA}}=$ gram equivalent of gallic acid $(170.2 \mathrm{~g} / \mathrm{eq})$

\section{Phytochemical screening}

The qualitative phytochemical composition of air dried fruiting bodies of Coprinus comatus and Pleurotus cystidiosus was determined following the procedures of Sofowora (1993), Trease and Evans (1989) and Harborne (1973) as cited by Edeoga et al. (2005).

\section{Results \& Discussion}

\section{Antibacterial assay}

The antibacterial activity of ethanol and acetone extracts of fruiting bodies of Coprinus comatus and Pleurotus cystidiosus was evaluated against gram negative Escherichia coli and gram positive Staphylococcus aureus. As shown in Table 1, ethanol and acetone extracts of both 
Table 1 Zone of inhibition (mm) of Coprinus comatus and Pleurotus cystidiosus extracts against Staphylococcos aureus and Escherichia coli after 24 hours of incubation

\begin{tabular}{lcc}
\hline Extracts & Staphylococcos aureus & Escherichia coli \\
\hline Coprinus comatus ethanol extract & $14.09 \pm 4.65$ & - \\
Pleurotus cystidiosus ethanol extract & $13.43 \pm 0.15$ & - \\
Coprinus comatus acetone extract & $13.16 \pm 3.39$ & - \\
Pleurotus cystidiosus acetone extract & $15.25 \pm 2.76$ & - \\
Coprinus comatus immobilized myelia & - & - \\
Pleurotus cystidiosus immobilized mycelia & - & - \\
Streptomycin & $26.50 \pm 0.50$ & $28.50 \pm 1.08$ \\
\hline
\end{tabular}

- No zone of inhibition

Size of disc $=6 \mathrm{~mm}$

Data are presented as mean \pm SD of three replications

mushroom species inhibited the growth of Staphylococcus aureus. Coprinus comatus ethanol extract produced wider zone of inhibition with a mean value of $14.09 \mathrm{~mm}$ compared to acetone extract with a mean value of $13.43 \mathrm{~mm}$. On the contrary, Pleurotus cystidiosus acetone extract registered larger zone of inhibition with a mean of $15.25 \mathrm{~mm}$ than the ethanol extract with a mean of $13.16 \mathrm{~mm}$. The ethanol and acetone extract of both mushroom species showed no antibacterial activity against Escherichia coli. Moreover, the immobilized mycelial discs did not exhibit antibacterial activity against both test organisms.

The results of the present study demonstrated antibacterial activity of ethanol and acetone extracts of Coprinus comatus and Pleurotus cystidiosus against Staphylococcos aureus but ineffective against Escherichia coli. This indicates that the extracts evaluated have narrow spectrum of antibacterial activity. The finding in this study corroborates the results of Dulay et al. (2014) who reported that the ethanolic extract of Lentinus tigrinus showed high antibacterial activity against Staphylococcos aureus but not against Escherichia coli. Moreover, Turkoglo et al (2007a, 2007b) disclosed that the extracts of Russula delica and Laetiporus sulphureus have narrow antibacterial spectrum. The extracts showed more potent activity against gram positive than gram negative bacteria. Moreover, Neelam and Singh (2013) reported that Pleurotus florida and Pleurotus ostreatus ethanolic extract inhibited the growth of both gram positive and gram negative bacteria. Srivastava and Sharma (2011) revealed that the antimicrobial activity of mushroom varied according to the solvent used for macrofungal extract and the strain of basidium of fungus used. For instance, Iwalokun et al. (2007) found that petroleum ether and acetone extracts of Pleurotus ostreatus inhibited gram positive and gram negative bacteria as well as fungi. However, petroleum ether extract exhibited greater anti gram negative bacterial activity than the acetone extract. Methanol extract of Lyophylum decastes showed more effective inhibitory activity against bacteria than acetone and ethanol extract while acetone extract exhibited maximum activity against fungal cultures (Pushpa and Purushothama 2010). Manega et al. (2012) found out that Pleurotus florida aqueous, ethanolic and methanolic extracts strongly inhibited the growth of both gram positive and gram negative bacteria whereas ethyl acetate and hexane extracts showed low antimicrobial activity.

The absence of antibacterial activity of immobilized mycelial discs obtained in this study indicates that the bioactive components of mycelia of the two mushroom species are inactive. However, this does not conform to the results of other researchers. For instance, the immobilized secondary mycelia of Schizophyllum commune exhibited antibacterial activity against Escherichia coli and Staphylococcos aureus (Reyes et al. 2006) and Lentinus tigrinus against Staphylococcos aureus but not against Escherichia coli (Dulay et al. 2014). Kalyonecu et al. (2010) disclosed that many of the mycelia culture extract of wild mushroom species have weak antimicrobial activity. 
Table 2 Radical Scavenging Activity and Total Phenolic Content of Pleurotus cystidiosus and Coprinus comatus

\begin{tabular}{lcc}
\hline Species & $\begin{array}{c}\text { DPPH Free Radical } \\
\text { Scavenging Activity }(\%)\end{array}$ & $\begin{array}{c}\text { Total Phenolic Content } \\
\text { (mg GAE/g) }\end{array}$ \\
\hline Coprinus comatus & $66.59 \pm 0.83$ & $17.82 \pm 0.51$ \\
Pleurotus cystidiosus & $72.97 \pm 0.68$ & $3.41 \pm 0.12$ \\
Ascorbic acid & $91.90 \pm 0.50$ & \\
\hline
\end{tabular}

Data presented are means \pm SD of three replications.

\section{DPPH free radical scavenging activity}

The antioxidant activity was analyzed by DPPH free radical scavenging assay. This method is widely used in evaluating the antioxidant activity because of relative short time of analysis in comparison to other methods (Mujic et al. 2010). It relies on the reduction of methanolic DPPH solution in the presence of a hydrogen donating compound (antioxidant) (Abdulla et al. 2012). The radical scavenging activity of the extracts on DPPH is presented in Table 2. Both species scavenged DPPH radical, however, Pleurotus cystidiosus registered higher DPPH scavenging activity compared to Coprinus comatus. This result implies that although both mushroom species can inhibit free radical formation and scavenging activity, significant variation exists between the two species evaluated. Similar results were previously reported in literature (Unekwo 2014). However, the values obtained in this study were lower than ascorbic acid (control). This finding is congruent with the observation of Peteros and Uy (2010) who reported that the scavenging activity of four species of Philippine medicinal plants were not comparable to L - ascorbic acid since crude extracts and pure commercial form of ascorbic acid were used in the analysis. The bioactive compounds responsible for antioxidant activity should be isolated and purified to obtain comparable if not higher bioactivity. The result of the present study indicated that Coprinus comatus and Pleurotus cystidiosus contain bioactive compounds with antioxidant activity. This finding supports previous works that demonstrated antioxidant properties of different mushroom species namely: Pleurocybella porringens, Lentinus squarossolus and Volvariella esculenta (Okoro 2012), Ganoderma lucidum (Joseph et. al 2009), and Pleurotus ostreatus (Jakuyamar et al. 2009).

\section{Total phenolic content}

Phenolic acids are aromatic secondary metabolites that are widely distributed throughout the plant kingdom (Robins, 2003). However, recently these compounds have also been reported in various species of mushrooms (Puttaraju et al. 2006, Palacios et al. 2011, Abdullah et al. 2012, Gan et al. 2013). Phenolic compounds are one of the groups of non-essential dietary components that have been associated with the inhibition of artherosclerosis, cancer and inflammation (Puttaraju et al. 2006, Sarikurkcu et al. 2010). In this study, the total phenolic content was determined by Folin Ciocalteau method and the results were expressed as $\mathrm{mg}$ gallic acid equivalents per gram (mg GAE/g) of air dried mushrooms. Table 2 also presents the total phenolic concentration of Coprinus comatus and Pleurotus cystidiosus. Of the two mushroom species analyzed, Coprinus comatus registered higher phenolic content than Pleurotus cystidiosus. The total phenolic content of Coprinus comatus obtained in this study was higher than the reported values of Lentinula edodes (11.70 mg GAE/g) and Hericium erinacius (7.80 mg GAE/g) by Mujic (2010), Leucopaxillus giganteus $(6.29 \mathrm{mg} / \mathrm{g})$, Sarcodon imbraticus $(3.76 \mathrm{mg} / \mathrm{g})$ and Agaricus arvensis $(2.83 \mathrm{mg} / \mathrm{g})$ by Barros et al. (2007) but lower than Agrocybe aegerita (23.07 mg GAE/g) by (Mujic 2010). Moreover, Pleurotus cystidiosus exhibited lower value than those reported by Gan et al. (2013) and Mujic (2010). Puttaraju et al. (2006) disclosed that the amount of phenolic compounds depends on the species of mushrooms. They classified mushrooms into three groups on the basis of their phenolic content as low, moderate and high phenolic species. Termitomyces heimii and Helveria crispa ranked as high phenolic species. In a related study, Barros et al. (2007) reported that the total phenolics contents were the major antioxidant component found in Leucophaxillus giganteus, 
Sarcodon imbricatus and Agaricus arvensis extracts. The total phenolic content is correlated with DPPH free radical scavenging activity of mushrooms (Abdullah et al. 2012, Okoro 2012).The total phenolic content of the mushroom extracts can be related to their antioxidant capacities.

\section{Phytochemical analysis}

Phytochemicals are bioactive non nutrient plant compounds in fruits, vegetables, grains and other plant foods that have been linked to reducing the risks of major chronic diseases (Liu 2004). Phytochemicals have also been reported in various species of mushrooms (Asuquo and Etim 2011, Adebayo et al. 2012, Afiukwa et al. 2013, Unekwo et al. 2014). The qualitative phytochemical composition of Philippine wild strains of Coprinus comatus and Pleurotus cystidiosus is shown in Table 3. Alkaloids, saponins, flavonoids and terpenoids were present in both species. Cardiac glycosides and steroids were absent in Pleurotus cystidiosus while tannins were not detected in both species. The result of the present study is in agreement with the previous reports that mushrooms are rich in phytochemicals. For example, Adebayo et al. (2012) reported that alkaloids, saponins, steroids, phlobatanins, flavonoids and anthraquinones were present in metabolite of Pleurotus pulmonarius. Wandati et al. (2013) disclosed that saponins, polyphenols and terpenoids were present while alkaloids, tannins and anthraquinones were not detected in wild edible mushrooms from selected areas in Kenya.

Table 3 Phytochemical composition of Coprinus comatus and Pleurotus cystidiosus fruiting bodies

\begin{tabular}{lcc}
\hline Phytochemicals & Coprinus comatus & Pleurotus cystidiosus \\
\hline Alkaloids & + & + \\
Cardiac glycosides & + & - \\
Flavonoids & + & + \\
Saponins & + & + \\
Steroids & + & - \\
Tannins & - & - \\
Terpenoids & + & + \\
\hline
\end{tabular}

+ present

- not detected

A number of mushroom species have been reported to contain alkaloids, saponins, flavonoids and tannins such as Oxysporus populous (Asuquo and Etim, 2011), Agaricus bisporos, Lentinus sajor caju and coral mushroom (Afiukwa et al. 2013), Cantharellus cibarius, Termitomyces robustos, Termitomyces manniformis, Pleurotus pulmonarius, Pleurotus ostreatus, Lactarius deliciosus, Auricularia auricula, Hericium erinacius (Unekwo et al. 2014). Phytochemicals are responsible for many biological activities and pharmacological properties. Flavonoids are widely distributed group of polyphenolic compounds with health related properties Del-Rio et al. 1997). They have long been recognized to posses anti-inflammatory, anti-allergic, hepatoprotective, antithrombotic, anti-viral, and anti-carcinogenic activities (Tapas et al., 2008).

Saponins play an important role in chemical defense and posses a wide spectrum of pharmacological effects (Caulier et al. 2011) such as anti-viral, prevention of cancer by preventing DNA from damage and inhibition colon cancer (Eze \& Ernest 2014), precipitation and coagulation of red blood cells (Yadav \& Agarwala 2011) and posses anti-inflammatory and antidiabetic properties (Lee et al., 2012 as cited by Wandati et al. 2013). Tannins have stringent properties, hasten the healing of wounds and inflamed mucous membranes (Okwu and Josiah 2006) and prevent development of microorganisms by precipitating microbial proteins (Fakoya and Oloketuyi 2012). Cardiac glycosides present in Pappea capensis have been shown to aid in treatment of congestive heart failure and cardiac arythmia (Karau et al. 2012). Alkaloids are secondary metabolites found in living organisms with pharmacological properties (Robert \& Wink 1998). They play an important role in the defense systems against pathogens and animals (Patel et 
al. 2012) and exhibit anti-inflammatory activity (Barbosa-Filho et al 2006). Terpenoids isolated from some basidiomycota showed antibacterial activity against Staphylococcos aureus, Ralstonia solanacearum, Micrococcos roseus, Escherichia coli and Bacillus brevis (Ghosh 2014). A large number of terpenopids exhibit cytotoxicity against a variety of tumor cells and cancer preventive as well as anti-cancer efficacy in pre clinical models (Thoppil and Bishayee 2011).

\section{Acknowledgements}

This research was funded by Philippine Rice Research Institute through research fellowship program. The authors would like to acknowledge the technical assistance extended by the research staff of Rice Chemistry Division, Philippine Rice Research Institute and Center for Tropical Mushroom Research and Development Center, Central Luzon State University.

\section{References}

Abdulla N, Ismael SM, Aminudin N, Shuib AS, Lau BF. 2012 - Evaluation of selected culinary medicinal mushroom for antioxidant and ACE inhibitory activities. Evidence Based Complementary Alternative Medicine 2012:1-12.

Adebayo, EA, Oloke JK, Ayandale AA, Adegunlola CO. 2012 - Phytochemical, antioxidant and antimicrobial assay of mushroom metabolite from Pleurotus pulmunarius. J. Microbiol. Biotech. Res. 2 (2), 366-374.

Adom KK, Liu RH. 2002 - Antioxidant activity of grains. J. Agric Food Chem. 50, 6182-6187.

Afiukwa CA, Ugwu, Okechukwu PC, Ebenyi LN, Ossai Emmanuel C, Nwaka Andrew C. 2013 Phytochemical analysis of three wild edible mushrooms, coral mushroom, Agaricus bisporus and Lentinus sajor caju, common in Ohaukwu Area of Ebonyi State, Nigeria. Int J Pharm 3 (2): 410-414.

Asuquo JE, Etim EE. 2011 - Phytochemical and anti-nutrients evaluation of Oxyporus populinus. Journal of Emerging Trends in Engineering and Applied Sciences, 2 (5): 817-820 .

Barbosa-Filho JM, Piuvezam MR, Moura MD, Silva MS, Batista Lima KB, Leitao da Cuncha EV, Fechine IM, Takemura OS. 2006 - Anti-inflammatory activity of alkaloids: A twenty century review. Brazilian Journal of Pharmacognosy 16 (1): 109-139 .

Barros L, Ferreira MJ, Queiros B, Ferreira ICFR, Baptista P. 2007 - Total phenols, ascorbic acid, $\mathrm{B}$ carotene and lycopene in Portuguese wild edible mushrooms and their antioxidant activities. Food Chemistry 103: 413-419.

Caulier, GC, Dyck SV, Gerbaux P, Eeckhaul I, Flammang P. 2011 - Review of saponin diversity in sea cucumbers belonging to the family Holothuridae. SPC Beche de mer Information Bulletin 31: 48-54 .

Cuevas, MC, Reyes RG and Kalaw SP. 2009 - Biophysiology of Lentinus sajor caju. Journal of Tropical Biology 7:48.

De Leon AM, Luangsa-ard JJD, Karunarathna SC, Hyde KD, Reyes RG, De La Cruz TEE. 2013a - Species listing, distribution, and molecular identification of macrofungi in six Aeta tribal communities in Central Luzon, Philippines. Mycosphere 4 (3), 478-494.

De Leon, AM, Reyes RG, De la Cruz TEE. 2013b - Enriched cultivation of three wild strains of Lentinus tigrinus (Bull) Fr. using agricultural wastes. Journal of Agricultural Technology 9(5), 1199-1214.

Del-Rio A, Obdululio BG, Castfillo J, Martin FG, Ortuno A. 1997 - Uses and properties of citrus flavonoids. J. Agric Food Chem. 45, 4505-4515.

Dulay, RMR, Kalaw SP, Reyes RG, Cabrera E, Alfonso N. 2012 - Optimization of culture conditions for mycelial growth and basidiocarp production of Lentinus tigrinus (Bull) Fr., A new record of domesticated wild edible mushroom in the Philippines. Philippine Agricultural Scientist 95 (3), 209-214.

Dulay, RMR, Arenas MC, Kalaw SP, Reyes RG, Cabrera EC. 2014 - Proximate composition and functionality of culinary - medicinal tiger sawgill mushroom, Lentinus tigrinus (higher 
basidiomycetes), from the Philippines. International Journal of Medicinal Mushrooms 16, (1): 85-94.

Edeoga, HO, Okwu DE, Mbaebie BO. 2005 - Phytochemical constituents of some Nigerian medicinal plants. African Journal of Biotechnology 4 (7), 685-688.

Ellamar, JB, Batu EB, Reyes RG. 2009 - Conservation of wild mycorural resources as food and medicine: Key towards strengthened rural participation in poverty alleviation and biodiversity conservation. Journal of tropical Biology 7: 17-24.

Eze SO, Ernest O. 2014 - Phytochemical and nutrient evaluation of leaves and fruits of Nuclealatifolia (Uvuru-ilu). Communications in Applied Sciences 2 (1), 8-24.

Fakoya SS, Oloketuyi SF. 2012 - Antimicrobial efficacy and phytochemical screening of mushrooms, Lenzites betulinus, and Coriolopsis gallica extracts. TAF Preventive Medicine Bulletin 11(6), 695-698.

Gan CH, Nurul Amira B, Asmah R. 2013 - Antioxidant analysis of different types of edible mushrooms (Agaricus bisporous and Agaricus brasiliensis). International Food Research Journal 20 (3), 1095-1102.

Ghosh SK. 2014 - Isolation of polysaccharide and terpenoids from some basidiomycota and their bacterial activities. British Microbiology Research Journal 4 (2), 155-156.

Iqbal S, Bhanger MI, Anwar F. 2005 - Antioxidant properties and components of commercially available varieties of rice. Food Chemistry 93, 265-272.

Iwalokun BA, Usen, UA, Otunda AA, Olukaya DK. 2007 - Comparative phytochemical evaluation, antimicrobial and antioxidant properties of Pleurotus ostreatus. African Journal of Biotechnology 6 (5), 1732-1739.

Jayakumar T, Thomas PA, Geraldine P. 2009 - In vitro antioxidant activities of an ethanolic extract of the oyster mushroom, Pleurotus ostreatus. Innovative Food Science and Emerging Technologies 10, 228 -234.

Joseph S, Sabulal B, George V, Smina TP, Janardhanan KK. 2009 - Antioxidative and antiinflammatory activities of the chloroform extract of Ganoderma lucidum found in South India. Sci Pharm. 77, $111-121$.

Kalyonecu F, Oskay M, Saglam H, Erdogan TF, Tamer, AU. 2010 - Antimicrobial and antioxidant activities of mycelia of ten mushroom species. J. Med. Food. 13 (2), 415-419.

Karau GM, Njagi ENM, Machocho AK and Wangai LN. 2012 - Phytonutrient, mineral composition and in vitro antioxidant activity of leaf and stem bark powders of Pappea capensis. Pakistan Journal of Nutrition 11 (2), 123-132.

Liu, RH. 2004 - Potential synergy of phytochemicals in cancer prevention: Mechanism of action. The Journal of Nutrition. 3479S -3485S.

Menaga D, Mahalingam PU, Rajakumar S, Ayyasamy PM. 2012 - Evaluation of phytochemical characteristics and antimicrobial activity of Pleurotus florida mushroom. Asian Journal of Pharmaceutical and Clinical Research 5(4), 102-106.

Mujic I, Zekovic Z, Lepojevic Z, Vidovic S, Zivkivic J. 2010 - Antioxidant properties of selected edible mushroom species. Journal of Central European Agriculture 4 : 387-392.

Neelam S, Singh S. 2013 - Comparative in vitro studies on phytochemical and antibacterial properties of ethanolic extracts of Plerotus florida and Pleurotus ostreatus. Int J Pharm Bio Sci. 4 (3), 396-400.

Okoro IO. 2012 - Antioxidant activities and phenolic contents of three mushroom species, Lentinus squarrosulus Mont., Volvariella esculenta (Massee) Singer and Plerocybella porrigens (Pers.) Singer. Int. J. Nutr. Metab. 4(5), 72-76.

Okwu DE, Josiah C. 2006 - Evaluation of the chemical composition of two Nigerian medicinal plants. African Journal of Biotechnology 5(4), 357-361.

Palacios I, Lozano M, Moro C, D'Arrigo M, Rostagno MA, Martinez JA, Garcia-Lafuente A, Guillamon E, Villares A. 2011 - Antioxidant properties of phenolic compounds occurring in edible mushrooms. Food Chemistry 128, 674-678. 
Patel K, Gadewar M, Tripathi R, Parasad SK, Patel DK. 2012 - A review on medicinal importance, pharmacological activity and bioanalytical aspect of beta - carboline alkaloid "Harmine". Asian Pacific Journal of Tropical Biomedicine 660-664.

Peteros NP, Uy MM. 2010 - Antioxidant and cytotoxic activities and phytochemical screening of four Philippine medicinal plants. Journal of Medicinal Plants Research 4 (5), 407-414.

Pushpa H, Purushothama KB. 2010 - Antimicrobial activity of Lyophylum decastes an edible wild mushroom. World Journal of Agricultural Sciences 6 (5), 506-509.

Puttaraju NG, Venkatesaiah SU, S. M. Dharmesh SM, Urs SMN, Somasundaram R. 2006 Antioxidant activity of indigenous edible mushrooms. Journal of Agricultural and Food Chemistry 54, 9764-9772.

Reyes RG, Abella EA, Eguchi F, Iijima T, Higaki M. 2004 - Physiology of Collybia reinakeana, a wild endemic edible mushroom from Puncan forest, Caranglan, Nueva Ecija, Philippines. The Journal of Tropical Biology 3, 11-19.

Reyes RG, Abella EA, Gatdula GG. 2006 - Schizophyllum commune, a wild edible mushroom in the Philippines as source of ethnomycological nutriceuticals. Journal of Nature Studies 5 (1), 135-139.

Reyes RG, Lopez LLM, Kalaw SP, Kumakura K, Kikukawa T, Eguchi F. 2009a - Coprinus comatus, a newly domesticated wild nutriceutical mushroom in the Philippines. Journal of Agricultural Technology 5 (2), 229-316.

Reyes RG, Eguchi F, Kalaw SP, Kikukawa T. 2009b - Mushroom Growing in the Tropics. A Practical Guide. Central Luzon State University.

Reyes RG, Kalaw SP, Dulay RMR, Gonzaga R, Yoshimoto H, Kikukawa T and Eguchi F. 2009c Amino Acid Profile and Anti-hypertensive Activity of Collybia reinakeana P. Henn. Philippine Agricultural Scientist 93(3), 263-268.

Reyes RG, Kalaw SP, Dulay RMR, Yoshimoto H, Miyazawa N and Eguchi F. 2013 - Philippine native and exotic species of edible mushrooms grown on rice straw based formulation exhibit nutraceutical properties. Philippine Agricultural Scientist. 9 (2), 198-204.

Roberts MF, Wink M. 1998 - Alkaloids: Biochemistry, ecology and medicinal applications. Penum press. New York. p 1-7.

Robbins RJ. 2003 - Phenolic Acids in Foods: An Overview of Analytical Methodology. J. Agric. Food Chem. 51 (10), 2866-2887.

Sarikurkcu C, Tepe B, Semiz DK, Solak MH. 2010 - Evaluation of metal concentration and antioxidant activity of three edible mushrooms from Mugla, Turkey. Food and Chemical Toxicology 48, 1230-1233.

Srivastava MP, Sharma N. 2011 - Antimicrobial activities of basidiocarp of some basidiomycetes strains against bacteria and fungi. J Mycol Plant Pathol 41 (2), 332-334.

Tapas, AR, Sakarkar DM, Kakde RB. 2008 - Flavonoids as nutraceutical: A review. Tropical Journal of Pharmaceutical Research 7(3), 1089-1099.

Tayamen MJT, Reyes RG, Floresca EJ, Abella EA. 2004 - Domestication of wild edible mushrooms a non timber forest products resources among the Aetas of Mt. Nagpale, Abucay Bataan: Ganoderma and Auricularia polytricha. The Journal of Tropical Biology 3: 49-51.

Thoppil RJ, Bishayee A. 2011 - Terpenoids as potential chemoprotective and therapeutics agents in liver cancer. World Journal of Hepatology 3 (9), 228-249.

Turkoglu A, Duru ME, Mercan N, Kivrak I, Gezer K. 2007a - Antioxidant and antimicrobial activities of Laetiporus sulphureus (Bull.) Murrill. Food Chemistry 101, 267-273.

Turkoglu A, Duru ME, Mercan N. 2007b - Antioxidant and antimicrobial activity of Russula delica Fr: an edible mushroom. Eurasian Journal of Analytical Chemistry, 2 (1) 54- 67.

Unekwo HR, Audu JA, Makun MH, Chidi EE. 2014 - Phytochemical screening and antioxidant activity of methanolic extract of selected wild edible Nigerian mushrooms. Asian Pacific Journal of Tropical Disease, 4 (Suppl 1): S153-S157. 
Wandati TW, Kenji GM, Onguso JM. 2013 - Phytochemicals in edible wild mushrooms from selected areas in Kenya. Journal of Food Research 2 (3), 137-144.

Yadav RNS, Agarwala M. 2011 - Phytochemical analysis of some medicinal plants. Journal of Phytology 3 (2), 10-14. 